\title{
A Case of Cleft Hypoplastic Maxilla corrected by Single-stage Lefort 1 Osteotomy to improve Esthetics and Function
}

\author{
${ }^{1}$ Pradeep Christopher, ${ }^{2}$ Bala Gughan, ${ }^{3}$ Poorna Devadoss, ${ }^{4}$ Naveen H Krishnamurthy
}

\begin{abstract}
Among the congenital anomalies, cleft lip and palate take about $14 \%$ of the total population; among them, unilateral cleft lip and palate is predominant than bilateral. Cleft lip correction preceding the cleft palate is usually done within a gap of 3 years. Due to the wide median palatal cleft, a perfectly performed Langenbeck pushback closures can leave behind persistent oronasal fistulas during the healing process, due to which severe scarring of palatal mucosa takes place. Secondary alveolar grafting is a procedure performed irrespective of the age for persistent oronasal fistulas. Further closure of nasal and palatal fistula with intervening bone graft is always successful but can compromise the growth of maxilla resulting in hypoplasia. In one such case of a failed secondary alveolar grafting, a Lefort 1 advancement alone was done not only to improve the facial esthetics but also function. This paper discusses in detail the comprehensive surgical procedure performed.
\end{abstract}

Keywords: Cleft-orthognathic surgery, Cleft secondary correction, Esthetic cleft surgeries.

How to cite this article: Christopher P, Gughan B, Devadoss $P$ Krishnamurthy $\mathrm{NH}$. A Case of Cleft Hypoplastic Maxilla corrected by Single-stage Lefort 1 Osteotomy to improve Esthetics and Function. J Health Sci Res 2015;6(1):25-27.

Source of support: Nil

Conflict of interest: None

\section{CASE REPORT}

A female patient born to nonconsanguineous parents reported to the Department of Oral and Maxillofacial Surgery, Thai Moogambigai Dental College and Hospital, Chennai with a chief complaint of unappealing facial features and difficulty in speech and swallowing; she

\footnotetext{
${ }^{1}$ Professor, ${ }^{2-4}$ Reader

${ }^{1}$ Department of Oral and Maxillofacial Surgery, Thai Moogambigai Dental College and Hospital, Chennai, Tamil Nadu, India

${ }^{2}$ Department of Oral and Maxillofacial Surgery, Karpaga Vinayaga Dental College, Chennai, Tamil Nadu, India

${ }^{3}$ Department of Orthodontics, Thai Moogambigai Dental College and Hospital, Chennai, Tamil Nadu, India

${ }^{4}$ Department of Pedodontics, Rajarajeswari Dental College and Hospital, Bengaluru, Karnataka, India

Corresponding Author: Pradeep Christopher, No. 2 LH Nagar 2nd Cross Street, Adambakkam, Chennai-600088, Tamil Nadu India, Phone: 09841759105, e-mail: p_ortho@yahoo.com
}

already had undergone repair for unilateral cleft lip and palate. Clinical examination revealed severe hypoplastic maxilla and on intraoral examination showed scarring of the palatal region from previous surgeries done to close the cleft palate, due to which the patient had difficulty in speech and also deglutation. History revealed that cleft lip correction was done at 1 year of age (1989), and at the age of 6 years (1994), cleft palate closure was done; both the procedures were done in Government Hospitals in Chennai. Later, when the patient was about 15 years of age (2005), bilateral sagittal split osteotomy (BSSO) was done in a private hospital in Chennai to set back the mandible. Again in the year 2009, iliac bone grafts were harvested and used for closing the palatal defect in a private institute, but the closure resulted in severe scarring and thus prevented the maxillary growth and resulted in severe maxillary hypoplasia (Fig. 1).

After discussing the case, it was planned for a Lefort 1 osteotomy with advancement up to $10-12 \mathrm{~mm}$ approximately in order to get a good esthetics as well as to improve function. The procedure was explained to parents and an informed consent was obtained.

\section{SURGICAL PROCEDURE}

Under nasoendotracheal intubation, general anesthesia was administered, intraoral incisions from first molar to first molar were made in the upper vestibule, and bone cuts were made from lateral piriform aperture and continued posteriorly up to the tuberosity area maintaining $5 \mathrm{~mm}$ above the roots of the maxillary teeth on both sides using a 701 surgical bur with a straight surgical hand piece; ${ }^{11}$
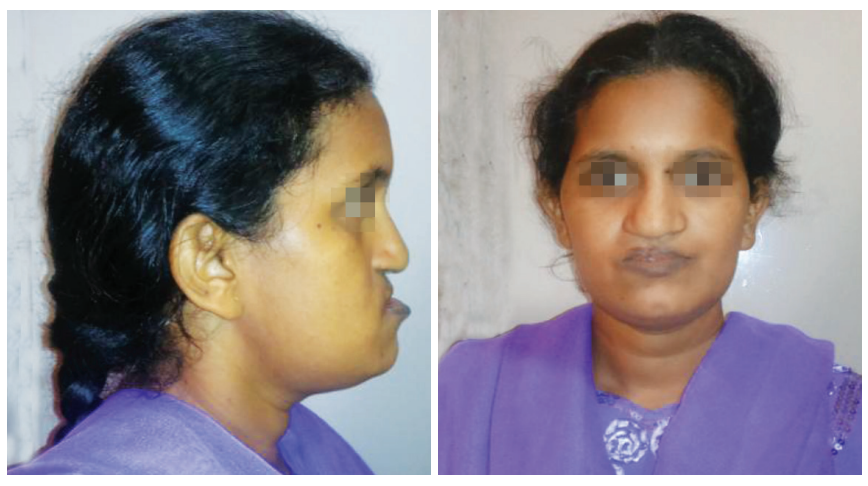

Fig. 1: Preoperative photographs 
lateral nasal osteotomes are used to separate the lateral nasal wall on both sides; then a septal osteotome was used to separate the septum; then, the pterygoid osteotomes are used to disjunct the maxilla from the pterygoid bone and a classical Lefort 1 down fracture is performed. ${ }^{5}$ After trimming the sharp margins and with the help of Tiesier maxillary mobilizer, the maxilla is mobilized and advanced anteriorly without any restrictions up to $11 \mathrm{~mm}$ approximately; fixation was done with two L-shaped, four-holed miniplates in the pyriform area and two straight four-holed mini plates in the buttress area (Fig. 2) after getting a good occlusion with the mandibular arch. The wound was sutured using 3-0 vicryl sutures after alar cinching ${ }^{8}$ to minimize widening of alar base and the patient was extubated; the postoperative recovery was uneventful.

\section{DISCUSSION}

Secondary alveolar grafting ${ }^{4}$ which was first described in $1970,{ }^{2}$ is one of the treatment modality in patients with unilateral and bilateral cleft lip and palate. ${ }^{10}$ Patients with cleft lip and palate require prolonged interdisciplinary approach and long-term follow-up to establish a final result. ${ }^{7}$

In early stages of cleft palate repair, bone grafts are usually used in closing the bony defects. ${ }^{6}$ In most of the cases, resorption of the graft occurs because of excessive tension in the mucoperiosteum and absence of physiologic stress by the erupting teeth ${ }^{4}$, which ultimately results in inadequate coverage or severe scarring of the palate; ${ }^{3}$ this can restrict maxillary growth and cause hypoplasia of the maxilla. ${ }^{12}$

Lefort 1 osteotomy is usually the surgery of choice to resolve abnormalities of jaw relationships, such as malocclusions, to correct facial esthetics, and to improve the speech. ${ }^{1}$

But $78.5 \%$ of surgeons prefer to do Lefort 1 osteotomy with advancement in patients who had already undergone primary closure of unilateral cleft lip and palate with maxillary hypoplasia. ${ }^{12}$

\section{CONCLUSION}

After the completion of skeletal growth in craniofacial region, the patient who has already undergone cleft lip and palate repair with secondary alveolar grafting ${ }^{9}$ exhibits a concave profile due to retarded maxillary growth and consequently tends to develop functional problems with speech, deglutition, and also obstructive sleep apnea. ${ }^{12}$ In this particular case, by doing a Lefort 1 osteotomy with advancement of approximately $11 \mathrm{~mm}$, we were not only able to get a good esthetic profile but also improve the function (Fig. 3). ${ }^{1}$
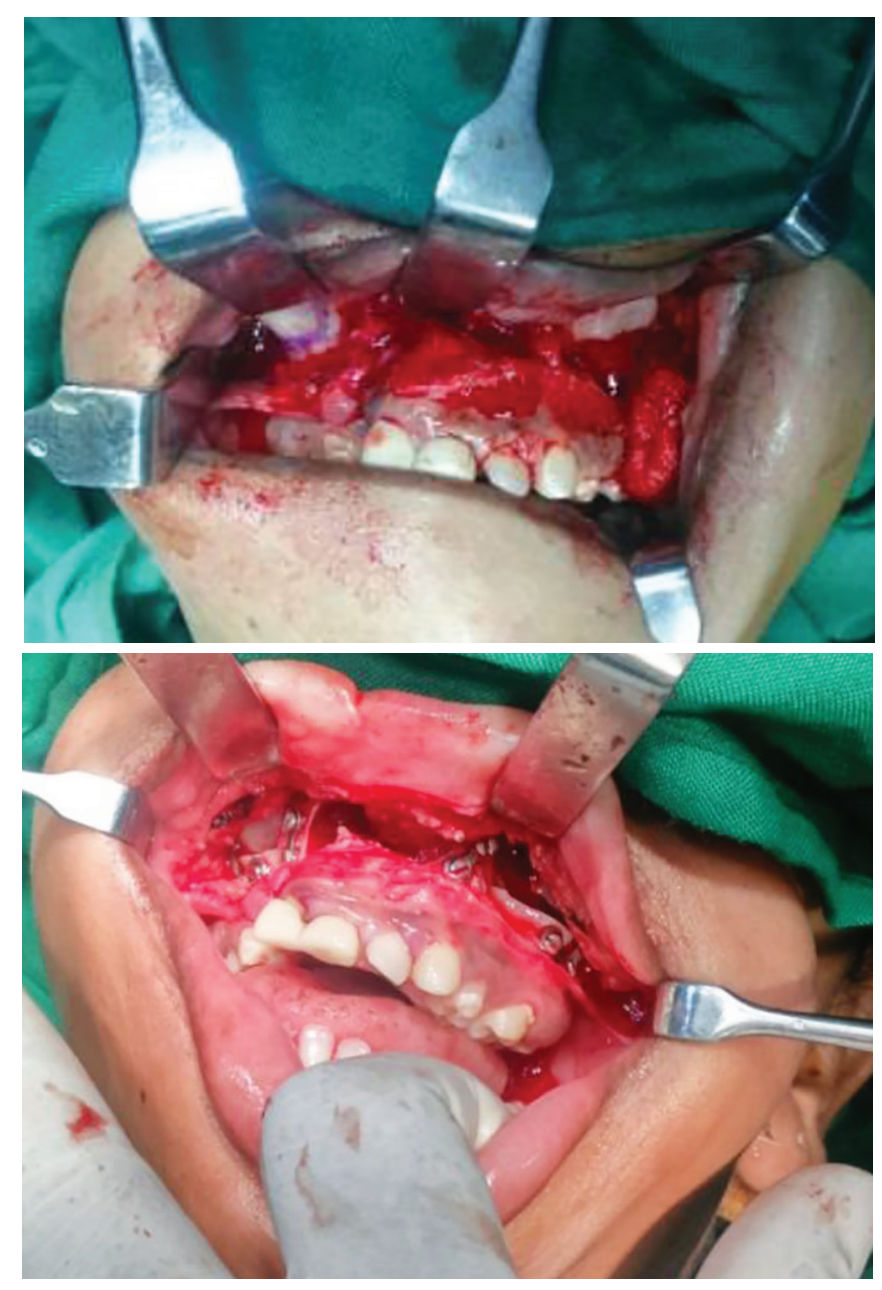

Fig. 2: Intraoperative photographs
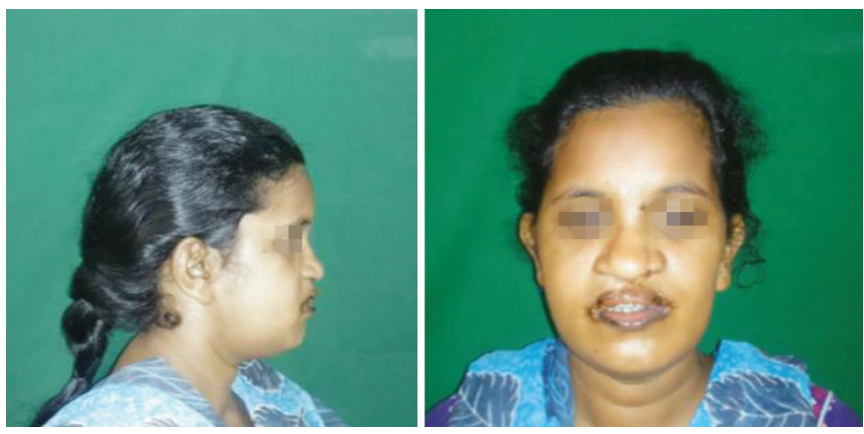

Fig. 3: Postoperative photographs

\section{REFERENCES}

1. Kummer AW, Strife JL, Grau WH, Creaghead NA, Lee L. The effects of Le Fort I osteotomy with maxillary movement on articulation, resonance, and velopharyngeal function. Cleft Palate J 1989 Jul;26(3):193-199.

2. Collins M, James DR, Mars M. Alveolar bone grafting: a review of 115 patients. Eur J Orthod 1998 Apr;20(2):115-120.

3. Jia YL, James DR, Mars M. Bilateral alveolar bone grafting: report of 55 consecutively treated patients. Eur J Orthod 1998 Jun;20(3):299-307.

4. Jai YL, FUMK, et al. Morden outcome of secondary alveolar bonegrafting patients with varies types of cleft. Br J Oral Maxillofac Surg 2006 Aug;44(4):308-312. 
5. Phoebe MG, John BM, Bonnie LP. Frequency of Lefort 1 osteotomy after repaired cleft lip and palate or cleft palate. Cleft Palate Craniofac J 2007 Jul;44(4):396-401.

6. Kim KR, Kim S, Baek SH. Change in grafted secondary alveolar bone in patients with UCLP and UCLA. Angle Orthod 2008 Jul;78(4):631-640.

7. Marukawa E, Oshina H, Iino G, Morita K, Omura K. Reduction of bone resorption by the application of platelet rich plasma (PRP) in bone grafting of the alveolar cleft. J Craniomaxillofac Surg 2011 Jun;39(4):278-283.

8. Ahemed A, Sondos A. A protocol used to manage maxillary hypoplasia in cleft lip and palate patients. Open J Stomatol 2012;2:130-135

9. Al-Nawas B, Wriedt S, Reinhard J, Keilmann A, Wehrbein H, Wagner W. Influence of patient age and experience of the surgeons on early complication after surgical closure of the cleft palate: a retrospective cohort study. J Craniomaxillofac Surg 2013 Mar;41(2):135-139.

10. Fonseca RJ, Marciani RD, Turvey TA. Oral and maxillofacial surgery. Section 3, cleft and craniofacial surgery. 2nd ed. United States: Elsevier Health Sciences; 2008.

11. Posnick JC, Principles and practice of orthognathic surgery. Chapter 4, Heriditary, developmental and environmental influences on the formation of dentofacial deformities; 9th ed. USA: Saunders, Elsevier; 2015. p. 1864.

12. Posnick JC. Principles and practice of orthognathic surgery. Chapter 8, Speech, mastication and swallowing considerations in evaluation and treatment of dentofacial deformities; 9th ed. USA: Saunders, Elsevier; 2015. p. 1864. 